\title{
GABAergic innervation of the ciliary ganglion in macaque monkeys - A light and electron microscopic study
}

\author{
Miriam Barnerssoi ${ }^{1}$, Paul J. May ${ }^{2}$, and Anja K. E. Horn ${ }^{1}$ \\ ${ }^{1}$ Institute of Anatomy and Cell Biology I, Ludwig-Maximilian Universität, Munich, Germany \\ ${ }^{2}$ Departments of Neurobiology and Anatomical Sciences, Ophthalmology, and Neurology, \\ University of Mississippi Medical Center, Jackson, MS 39216
}

\begin{abstract}
The vertebrate ciliary ganglion (CG) is a relay station in the parasympathetic pathway activating the iris sphincter and ciliary muscle to mediate pupillary constriction and lens accommodation, respectively. While the postganglionic motoneurons in the CG are cholinergic, as are their inputs, there is evidence from avian studies that GABA may also be involved. Here, we used light and electron microscopic methods to examine the GABAergic innervation of the CG in Macaca fascicularis monkeys. Immunohistochemistry for the gamma aminobutyric acid synthesizing enzyme glutamic acid decarboxylase (GAD) and choline acetyltransferase (ChAT) revealed that all CG neurons are contacted by ChAT-positive terminals. A subpopulation of $17.5 \%$ of CG neurons was associated with terminal boutons expressing GAD-immunoreactivity in addition. Doublelabeling for GAD and synaptophysin confirmed that these were synaptic terminals. Electron microscopic analysis in conjunction with GABA-immunogold staining showed that (1) GADpositive terminals mainly target dendrites and spines in the perisomatic neuropil of CG neurons;

(2) GABA is restricted to a specific terminal type, which displays intermediate features lying between classically excitatory and inhibitory endings; and (3) if a CG neuron is contacted by GABA-positive terminals, virtually all perisomatic terminals supplying it show GABA immunoreactivity. The source of this GABAergic input and whether GABA contributes to a specific CG function remains to be investigated. Nevertheless, our data indicate that the innervation of the ciliary ganglion is more complex than previously thought, and that GABA may play a neuromodulatory role in the control of lens or pupil function.
\end{abstract}

\section{Keywords}

cotransmission; lens; parasympathetic; pupil; RRID:AB_2079751; RRID:AB_90715; RRID: AB_2199013; RRID: AB_47765; RRID:SCR_014199; RRID:SCR_003070; RRID:SCR_014235

Correspondence: Anja K. E. Horn, Institute of Anatomy and Cell Biology I, Ludwig-Maximilians Universität, Pettenkoferstraße 11, 80336 Munich, Germany. anja.bochtler@med.uni-muenchen.de.

CONFLICT OF INTEREST

The authors declare that they have no conflict of interest.

AUTHOR CONTRIBUTIONS

All authors had full access to all the data in the study and take responsibility for the integrity of the data and the accuracy of the data analysis. Study concept and design: M.B., A.K.E.H. Acquisition of data: M.B., P.J.M. Analysis and interpretation of data: M.B., P.J. M., A.K.E.H. Drafting of the manuscript: M.B. Critical revision of the manuscript for important intellectual content: P.J.M., A.K.E.H. Obtained funding: M.B., P.J.M., A.K.E.H. Technical and material support: P.J.M. Study supervision: P.J.M., A.K.E.H. 


\section{1 | INTRODUCTION}

The ciliary ganglion (CG) of vertebrates is a small cluster of nerve cells, located behind the ocular bulb, between the optic nerve and the lateral rectus muscle. It consists of parasympathetic, postganglionic, cholinergic neurons (Martin \& Pilar, 1963a; Landmesser \& Pilar, 1972) that are driven by preganglionic neurons in the Edinger-Westphal nucleus (EWpg) and project to the ciliary and sphincter pupillae muscles to mediate lens accommodation and pupillary constriction, respectively (Burde, 1967; Hultborn, Mori, \& Tsukahara, 1978; Martin \& Pilar, 1963b; Marwitt, Pilar, \& Weakley, 1971; Neuhuber \& Schrödl, 2011; Reiner, Karten, Gamlin, \& Erichsen, 1983). Physiological studies demonstrated that firing rates, recorded from macaque monkey EW units, are correlated with the activity of the ciliary and sphincter pupillae muscles (Gamlin, Zhang, Clendaniel, \& Mays, 1994; McDougal \& Gamlin, 2015). In birds, an additional subpopulation of CG neurons innervates the choroid (Neuhuber \& Schrödl, 2011; Reiner et al., 1983). Traditionally, it is believed that the CG receives its main preganglionic input from parasympathetic, cholinergic motoneurons of the EWpg, which corresponds to the cytoarchitecturally defined EW in monkey and birds (Gamlin \& Reiner, 1991; Gamlin, Reiner, Erichsen, Karten, \& Cohen, 1984; Horn, Eberhorn, Härtig, Ardeleanu, Messoudi, \& Büttner-Ennever, 2008; Kozicz et al., 2011; May, Reiner, \& Ryabinin, 2008a; May, Sun, \& Erichsen, 2008b; Narayanan \& Narayanan, 1976; Vasconcelos et al., 2003).

Immunohistochemical studies carried out in birds and mammals indicate that, besides the classical preganglionic cholinergic input to CG neurons, a peptidergic input is present (for review, see McDougal \& Gamlin, 2015; Neuhuber \& Schrödl, 2011). This includes the neuropeptides substance P, enkephalin (Erichsen, Karten, Eldred, \& Brecha, 1982a; Erichsen, Reiner, \& Karten, 1982b; Kirch, Neuhuber, \& Tamm, 1995; Zhang, Tan, \& Wong, 1994b), neuropeptide Y (Grimes, Koeberlein, Tigges, \& Stone, 1998), and calcitonin generelated peptide (CGRP) coexpressed with substance P (Kirch et al., 1995). Ultrastructural analysis using electron microscopic methods (EM) also demonstrated heterogeneity in preganglionic axon terminal properties (May \& Warren, 1993). All these observations indicate that transmission through the CG may, in fact, be more complex than previously thought.

In addition to peptides, there is evidence for GABA in the CG. Studies in chick provide strong evidence that the CG neurons are controlled by gamma amino butyric acid (GABA), which is known as a fast-acting transmitter. This is indicated by the expression of GABA-A receptors (McEachern, Margiotta, \& Berg, 1985), GABA-immunoreactive terminals on ciliary neurons in the chicken embryonic $\mathrm{CG}$, and the complete block of transmission through the chick CG after application of GABA in in-vitro and in-vivo studies (Liu, Neff, \& Berg, 2006; Tuttle, Vaca, \& Pilar, 1983). To the best of our knowledge, similar studies in mammals have not been carried out. To explore whether a GABAergic innervation of the CG is also present in mammals, we investigated the $\mathrm{CG}$ of macaque monkeys (Macaca fascicularis) using immunohistochemical methods in combination with light and electron microscopic techniques. 


\section{2 | MATERIALS AND METHODS}

\subsection{Animal procedures}

Ciliary ganglia (CG) from seven adult or young adult, male macaque monkeys (Macaca fascicularis), that had been sacrificed in the context of other research projects, were investigated in this study. At the time of sacrifice, the animals were sedated with a dose of ketamine hydrochloride ( $10 \mathrm{mg} / \mathrm{kg}$, i.m.) and deeply anesthetized with sodium pentobarbital $(100 \mathrm{mg} / \mathrm{kg}$, i.v.). Next, animals were transcardially perfused with $0.1 \mathrm{M}$, phosphate buffered saline (PBS) ( $\mathrm{pH} 7.2$ ), followed by a fixative containing $4 \%$ paraformaldehyde in $0.1 \mathrm{M}$, phosphate buffer ( $\mathrm{PB})(\mathrm{pH} 7.4$ ) for light microscopic examination (4 animals) or a mixture of 1.0\% paraformaldehyde (Fisher Chemical, Pittsburgh, PA) and $1.5 \%$ glutaraldehyde (Fisher Chemical) in $0.1 \mathrm{M}, \mathrm{PB}$ (pH 7.2) for electron microscopic studies (3 animals). All procedures were approved by the University of Mississippi Medical Center or Washington National Primate Research Center Institutional Animal Care and Use committees and were performed in accordance with National Institutes of Health policies.

\section{2 | Tissue processing for light microscopy}

The CG were removed from the orbit. After dissecting them free of connective tissue, they were equilibrated in $10 \%, 20 \%$, and $30 \%$ sucrose in $0.1 \mathrm{M} \mathrm{PBS} \mathrm{(pH} \mathrm{7.4)} \mathrm{for} \mathrm{frozen}$ sectioning. The ganglia were cut longitudinally at $10 \mu \mathrm{m}$ with a cryostat (HM, Thermo Scientific-Microm, Walldorf, Germany) and directly thaw-mounted onto glass slides (Superfrost Plus, M\&B Stricker, Oberschleissheim, Germany).

\section{3 | Antibody characterization}

2.3.1 | Glutamic acid decarboylase (GAD)—>In 4\% paraformaldehyde fixed tissue GABAergic terminals were detected with the rabbit polyclonal antibody against the two molecular isoforms glutamate decarboxylase 65 and 67 (AB1511, LOT NG173744444, Millipore, Billerica; http://antibodyregistry.org/AB_90715, Journal of Comparative Neurology Database) (Table 1). Whereas GAD65 is a membrane-anchored protein responsible for vesicular GABA production, the cytoplasmatic GAD67 is responsible for the basal levels of GABA synthesis. The immunogen was a synthetic peptide with the amino acid sequence [C]DFLIEEIERLGQDL from rat glutamate decarboxylase $\left(\mathrm{GAD}_{65}\right.$; $\mathrm{C}$ terminus residues [Cys] + 572-585). In western blot analysis the antibody (diluted 1:500) stains a doublet at approximately $65 / 67 \mathrm{kDa}$ on $10 \mu \mathrm{g}$ of mouse brain lysates (manufacturer's technical information). The antibody has been used previously at brainstem tissue of the same monkey species with a similar staining pattern around neurons (Zeeh, Hess \& Horn, 2013).

2.3.2 Gamma-aminobutyric acid (GABA)—For EM analysis of GABAergic terminals a rabbit polyclonal antibody against GABA (Sigma Aldrich, A2052, http:// antibodyregistry.org/AB_477652, Journal of Comparative Neurology Database) was used (Table 1). The immunogen was GABA-bound to bovine serum albumin (BSA). The GABA antibody shows positive binding with GABA and GABA-keyhole limpet hemocyanin, but not BSA, in dot blot assays (manufacturer's technical information). In cat and monkey tissue, this antibody has been shown to stain axon terminals at the EM level with 
postembedding immunogold staining in cat and monkey brainstem tissue (Bickford, Wei, Eisenback, Chomsung, Slusarczyk, \& Dankowsi, 2008; Wang, Perkins, Zhou, Warren, \& May, 2013).

2.3.3 | Choline acetyltransferase (ChAT)—Cholinergic motoneurons were detected with a polyclonal antibody against choline acetyltransferase (ChAT) raised in goat (AB144P, LOT LV1583390, Millipore, Billerica; http://antibodyregistry.org/AB_2079751, Journal of Comparative Neurology Database) (Table 1). The antibody is directed against the whole enzyme isolated from human placenta, which is identical to the brain enzyme (Bruce, Wainer, \& Hersh, 1985). In western blot analysis the antibody (diluted 1:1000) recognizes a 68- to 70-kDa protein on $10 \mu \mathrm{g}$ of mouse brain lysates (manufacturer's technical information). The appearance of ChAT-positive neurons in the present study are identical to data from previous reports of ChAT-positive neurons in the brainstem of the same monkey species after application of this ChAT antibody (Horn et al., 2008; May et al., 2008a).

2.3.4 Synaptophysin (Syn)-Synaptic nerve endings were detected with a monoclonal mouse antibody against synaptophysin (Dako; No. MO776; http://antibodyregistry.org/ AB_2199013) (Table 1). The antibody was obtained by immunization with coated vesicles of bovine brain tissue (Wiedenmann \& Franke, 1985) and recognizes a region between amino acids 269 and 289 in the cytoplasmic domain of synaptophysin. On a western blot of synaptic vesicle fraction from the mouse brain, it recognizes a single band of $38 \mathrm{kDa}$ (Wiedenmann \& Franke, 1985). The antibody produced a punctate staining in brain and eye muscle tissue in the same monkey species (Büttner-Ennever, Horn, Scherberger, \& D'Ascanio, 2001; Ugolini et al., 2006).

\section{4 | Combined immunoperoxidase labeling for GAD and ChAT}

The GABA synthetizing enzyme glutamic acid decarboxylase (GAD) is an established marker for cells and terminals that use the transmitter gamma aminobutyric acid (Erlander, Tillakalatne, Feldblum, Patel, \& Tobin, 1991). To detect GAD-immunoreactive neuronal profiles within the CG, a series of sections of each CG was processed for combined immunoperoxidase labeling for GAD and choline acetyltransferase (ChAT). Before and after pretreatment with $1 \% \mathrm{H}_{2} \mathrm{O}_{2}$ in $0.1 \mathrm{M}$ Tris buffered saline (TBS) (pH 7.4) for $30 \mathrm{~min}$ to suppress endogenous peroxidase activity, sections were washed in $0.1 \mathrm{M} \mathrm{TBS}$ (pH 7.4). To block unspecific binding sites, the sections were treated with 5\% normal horse serum in $0.3 \%$ Triton $\mathrm{X}-100$ in $0.1 \mathrm{M}$ TBS ( $\mathrm{pH} 7.4$ ) for $1 \mathrm{~h}$ at room temperature, then incubated in a 1:2000 dilution of rabbit anti-GAD 65/67 (Millipore Cat\# AB1511, RRID:AB_90715) in TBS with $5 \%$ normal horse serum in $0.3 \%$ Triton X-100 (Sigma) for $48 \mathrm{~h}$ at $4{ }^{\circ} \mathrm{C}$. After three washes in $0.1 \mathrm{M}$ TBS, the sections were incubated in biotinylated horse anti-rabbit IgG (1:200, Vector) in 0.1 M TBS ( $\mathrm{pH} 7.4$ ) containing 2\% bovine serum albumin (BSA) for $1 \mathrm{~h}$ at room temperature. After three washes in $0.1 \mathrm{M} \mathrm{TBS}(\mathrm{pH} 7.4)$, the sections were treated with ExtrAvidin-peroxidase (1:1000, Sigma) for $1 \mathrm{~h}$, washed and subsequently reacted with $0.025 \%$ diaminobenzidine $\mathrm{HCL}$ (DAB), $0.2 \%$ ammonium nickel sulfate and $0.015 \% \mathrm{H}_{2} \mathrm{O}_{2}$ in $0.05 \mathrm{M}$ TBS (pH 8.0) for 10 min to yield a black reaction product in GAD-positive neuronal profiles. After thorough washing and blocking of residual peroxidase activity in $1 \%$ $\mathrm{H}_{2} \mathrm{O}_{2}$ in $0.1 \mathrm{M}$ TBS ( $\mathrm{pH}$ 7.4) for $30 \mathrm{~min}$, the sections were again blocked with 5\% normal 
horse serum in $0.1 \mathrm{M}$ TBS ( $\mathrm{pH} 7.4$ ) containing $0.3 \%$ Triton $\mathrm{X}-100$ for $1 \mathrm{~h}$, and then incubated with goat anti-ChAT (1:100, Millipore Cat\# AB144P, RRID:AB_2079751) in 0.1 M TBS (pH 7.4) containing $0.3 \%$ Triton X-100 (Sigma) for $48 \mathrm{~h}$ at $4{ }^{\circ} \mathrm{C}$. After washing in 0.1 M TBS ( $\mathrm{pH} 7.4)$, the sections were incubated in biotinylated horse anti-goat IgG (1:200; Vector) in TBS containing $2 \%$ BSA for $1 \mathrm{~h}$ at room temperature. The antigen binding site was detected by incubating sections in Extravidin peroxidase (1:1000; Sigma) for $1 \mathrm{~h}$ and a subsequent reaction with $0.025 \% \mathrm{DAB}$ and $0.015 \% \mathrm{H}_{2} \mathrm{O}_{2}$ in $0.05 \mathrm{M}$ TBS ( $\mathrm{pH} 8.0$ ) for 10 min to yield a brown staining of cholinergic neuronal profiles. After washing, the sections were air-dried, dehydrated in alcohol, and coverslipped with DPX (Sigma).

\section{5 | Combined immunofluorescence labeling for GAD and Syn or GAD and ChAT}

To verify that GAD-positive bouton-like structures represent terminals, selected cryosections were immunolabeled for GAD and synaptophysin (Syn) (Dawson, Dawson, \& Snyder, 1992). To investigate whether GABAergic terminals within the CG also express ChAT immunoreactivity, selected cryosections were stained for ChAT and GAD using a doubleimmunofluorescence protocol. Sections were pretreated with 5\% normal donkey serum in $0.3 \%$ Triton $\mathrm{X}-100$ in $0.1 \mathrm{M}$ TBS ( $\mathrm{pH} 7.4$ ) for $1 \mathrm{~h}$ at room temperature. Then, sections were incubated in a cocktail containing rabbit anti-GAD 65/67 (1:500, Millipore, AB1511) and mouse anti-Syn (1:20, Dako Cat\# M0776, RRID:AB_2199013) or goat anti-ChAT (1:25, Millipore AB144P) in 5\% normal donkey serum with $0.3 \%$ Triton X-100 in $0.1 \mathrm{M}$ TBS (pH 7.4) for $48 \mathrm{~h}$ at $4{ }^{\circ} \mathrm{C}$. After three washes in TBS, sections were again treated with a cocktail containing Cy3-tagged donkey anti-rabbit IgG (1:200, Dianova, Jackson ImmunoResearch) and donkey anti-mouse or donkey anti-goat $\mathrm{IgG}$, tagged with the fluorescent dye Alexa 488 (1:200, Molecular Probes) in 0.1 M TBS (pH 7.4) and 2\% BSA for 1-2 h at room temperature. After several buffer rinses the slides were dried at room temperature. Fluorochrome-labeled sections were coverslipped with permanent aqueous mounting medium Gel/Mount (Biomeda, San Francisco, CA) and stored in the dark at $4{ }^{\circ} \mathrm{C}$.

\section{6 | Controls}

All antibodies were also applied to monkey brainstem and cerebellum sections and revealed staining patterns as known from previous studies (see Antibody Characterization).

\section{7 | Light microscopic analysis}

The slides were examined with one of two light microscopes (Leica; DMRB, Bensheim, Germany, or Zeiss; Axioplan, MicroImaging, Oberkochen, Germany), under either brightfield conditions or by using filters for red fluorescent $\mathrm{Cy}^{3}$ (Leica: N2.1; excitation filter BP 515-560 nm, dichromatic mirror $580 \mathrm{~nm}$, suppression filter LP $590 \mathrm{~nm}$; Zeiss: excitation filter BP $546 \mathrm{~nm}$, dichromatic beam splitter FT $580 \mathrm{~nm}$, barrier filter LP $590 \mathrm{~nm}$ ) and green fluorescent Alexa 488 (Leica: I3; excitation filter BP 450-490 nm, dichromatic mirror $510 \mathrm{~nm}$, suppression filter LP $515 \mathrm{~nm}$; Zeiss: excitation filter BP $475 \mathrm{~nm}$, dichromatic beam splitter FT $500 \mathrm{~nm}$, barrier filter LP $530 \mathrm{~nm}$ ). Photomicrographs were taken with a digital camera (Pixera Pro 600 ES, Klughammer, Markt Indersdorf, Germany) and processed in Photoshop 7.0 (Adobe Systems, Mountain View, CA; RRID:SCR_014199). Selected ChAT- and GAD-labeled immunofluorescence sections were examined with a laserscanning confocal microscope (Leica SP5, Mannheim, Germany). Z-series were collected 
every $0.49 \mu \mathrm{m}$ through every section. Dual-channel imaging of Alexa 488 and Cy3 fluorescence was sequentially recorded. Image stacks were processed by using ImageJ software (RRID:SCR_003070) (Schneider, Rasband, \& Eliceiri, 2012). The sharpness, contrast, and brightness were adjusted to reflect the appearance of the labeling seen through the microscope. In all flourescence images red color was converted to magenta for the benefit of color-blind readers (e.g., Fig. 1C,F,I) he figure panels were arranged and labeled with CorelDraw (version 11.0; Corel, Ottawa, Canada, RRID:SCR_014235).

\section{8 | Tissue processing for electron microscopy}

To extend the findings seen with light microscopy, we used electron microscopy techniques on paraformaldehyde/glutaraldehyde fixed monkey CG tissue. These CG sections were processed to allow investigation of their ultrastructure and for postembedding immunohistochemistry using immunogold labeling with an antibody to glutaraldehyde fixed GABA (Barnerssoi \& May, 2015). Specifically, after perfusion, the ganglia from 3 monkeys were removed from the orbit, dissected free of overlying connective tissue, cut in half, postfixed in the same fixative solution for 1 to $2 \mathrm{~h}$, and then stored in phosphate buffer (PB) at $4{ }^{\circ} \mathrm{C}$. Subsequently, the tissue was rinsed in $0.1 \mathrm{M} \mathrm{PB}(\mathrm{pH} 7.0)$, then treated for $2 \mathrm{~h}$ with $1 \%$ osmium tetroxide in $0.1 \mathrm{M} \mathrm{PB}(\mathrm{pH} 7.0)$. After several washes in deionized water, the tissue was dehydrated with increasing concentrations of acetone for 10 min each $(70 \%, 90 \%, 95 \%$, three times 100\%). The ganglia were embedded by placement in a 1:3 mixture of Durcupan ACM Epoxy (EM Sciences) and acetone overnight, then in a 3:1 mixture of Durcupan and acetone for $3 \mathrm{~h}$, and then in 100\% Durcupan for $1 \mathrm{~h}$. Finally, the CG were embedded in fresh $100 \%$ Durcupan, which was polymerized at $60{ }^{\circ} \mathrm{C}$ overnight. After trimming, a $1.0 \mu \mathrm{m}$ semithin section was taken from each block and stained with Toluidine Blue for orientation purposes. Ultrathin silver/gold sections, cut with a glass or a diamond knife on a microtome (Reichert Ultracut E) were mounted onto either 200 mesh copper grids for ultrastructural observation or onto nickel slot grids, treated with formvar (EM Sciences), for GABA postembedding. Sections on copper-mesh grids underwent routine electron microscopic staining processing, composed of treatment with $2.0 \%$ uranyl acetate (EM Sciences) for 3 min and calcinated lead citrate for $30 \mathrm{sec}$.

\section{9 | Postembedding immunogold for GABA}

Sections on formvar-coated, nickel slot grids were used for postembedding immunohistochemical staining for the presence of GABA containing terminals (for details see Barnerssoi \& May, 2015). These grids were etched with $3 \% \mathrm{H}_{2} \mathrm{O}_{2}$ for 3 min, rinsed three times with deionized water $\left(\mathrm{dH}_{2} \mathrm{O}\right)$, treated with $0.1 \mathrm{M}$ TBS $(\mathrm{pH}$ 7.4) and then incubated in $0.1 \mathrm{M}$ TBS (pH 7.4) containing $1 \%$ BSA for $30 \mathrm{~min}$. Subsequently, they were incubated in a 1:75 dilution of rabbit anti-GABA IgG (Sigma-Aldrich Cat\# A2052, RRID: AB_47765) in $0.1 \mathrm{M}$ TBS (pH 7.4) containing BSA and $0.05 \%$ Tween 20 overnight. Sections were then rinsed with TBS/BSA/Tween 20, followed by incubation in a 1:40 dilution of the secondary antibody (goat-anti-rabbit IgG conjugated to $15 \mathrm{~nm}$ gold particles, Aurion) in $0.1 \mathrm{M}$ TBS/BSA/Tween 20 for $2 \mathrm{~h}$. Grids were then rinsed again with and $\mathrm{dH}_{2} \mathrm{O}$. Finally, $2 \%$ glutaraldehyde in $0.1 \mathrm{M} \mathrm{PB}$ (pH 7.0) was used to fix the samples. Once again, uranyl acetate and calcinated lead citrate were used to stain the sections. All stained ultrathin sections were examined and photographed using a Zeiss Leo transmission electron microscope. 


\section{3 | RESULTS}

\section{1 | GABAergic inputs onto cholinergic, postganglionic CG neurons}

At the light microscopic level, combined immunoperoxidase staining for choline acetyltransferase (ChAT) and the GABA synthetizing enzyme glutamic acid decarboxylase (GAD) revealed that all CG somata exhibit moderate to strong ChAT immunoreactivity (Figure 1A, brown), while none of the cell somata stained positively for GAD (Figure 1A). Virtually all ChAT-positive CG neurons were found to receive input from attached boutonal endings expressing ChAT immunoreactivity at varying intensities (Figure 1A, arrows). In addition, numerous GAD-positive boutonal endings (Figure 1A, black), were found outlining the somata of a subpopulation of ChAT-positive CG neurons (Figure 1A, asterisks). The systematic quantitative analysis of $8 \mathrm{CG}$ (at least twenty $10 \mu \mathrm{m}$ sections per ganglion were quantified; spacing between sampled sections was $50 \mu \mathrm{m})$ revealed that $17.5 \%(16,860$ neurons were counted in total; 2,955 neurons out of these were supplied by GAD-positive boutons) of all CG neurons were associated with GAD-positive boutonal endings, and that these neurons were evenly distributed throughout the whole ganglion. The pattern of GADpositive innervation was striking: either a given CG neuron was densely covered by GADpositive boutonal structures or it was completely devoid of any GAD-positive input, as revealed by analysis of consecutive serial sections (Figure 1A). Scattered GAD-positive boutons that were not associated with CG somata were never detected.

\section{2 | GAD-positive boutons represent synaptic terminals}

To determine whether GAD-positive boutons represent synaptic terminals, we stained selected CG cryosections for GAD and synaptophysin (Syn) (Dawson et al., 1992), a glycopolypeptide that occurs in the membrane of presynaptic vesicles and therefore is commonly used as a marker for synaptic terminals (Rehm, Weidenmann, \& Betz, 1986). Virtually all CG neurons were densely supplied by green-fluorescing, Syn-positive terminals (Figure 1B). Those CG neurons receiving input from magenta-fluorescing, GAD-positive, bouton-like structures (Figure 1C, star) were surrounded by Syn-positive terminals that had an equivalent distribution (Figure 1B). The complete overlap of the immunostaining with these two antibodies (Figure 1D) indicates coexpression of Syn within all GAD-positive boutons, verifying that the GAD-positive bouton-like structures do in fact represent synaptic terminals. This analysis further revealed that none of the Syn-positive terminals around GAD-recipient CG neurons were GAD-negative, suggesting that no other inputs are present on these GAD-recipient neurons, based on whole cell analysis in serial sections.

\subsection{ChAT and GAD colocalize within CG terminals}

Since a coexpression of GAD and ChAT within terminals around CG neurons could not be ascertained from combined immunoperoxidase staining, double-immunofluorescence staining was used to explore whether GAD and ChAT colocalize in terminals associated with CG neurons receiving a GAD-positive input (Figure 1E-1J). Figure 1E shows a confocal image with cholinergic CG neurons (Figure 1E) and their surrounding terminals. Figure $1 \mathrm{~F}$ shows the same cells with GAD-positive terminals fluorescing magenta. These terminals supply a subpopulation of green-fluorescing, ChAT-positive, but GAD-negative somata (Figure 1F, stars). The overlay of these images revealed that all magenta-fluorescing 
GAD-positive terminals coexpressed green-fluorescing ChAT immunoreactivity (Figure 1G, 1J, white), but not all ChAT-positive terminals show GAD immunoreactivity (Figure 1J, green). An example of one such neuron is shown at higher magnification in Figure $1 \mathrm{H}$ to $1 \mathrm{~J}$. The cholinergic, GAD-negative neuron (arrow) is surrounded by cholinergic terminals (arrowheads in $\mathrm{H}$ ) that are GAD-positive (arrowheads in I). The magnified overlay demonstrates more clearly the coexpression of both markers (J, arrows).

\subsection{Ultrastructural analysis of the CG terminals}

After having demonstrated that GAD-positive, bouton-like structures around CG neurons represent terminals, the ultrastructural characteristics of these terminals were investigated. Synapses were identified by the presence of circumscribed pre- and postsynaptic densities around a synaptic cleft and the collection of vesicles in the presynaptic neuronal profile (Figure 2). The analysis of ultrathin sections of the monkey CG revealed that most of the synaptic contacts were located in the perisomatic neuropil that immediately surrounds each postganglionic motoneuron soma (Soma). Within the neuropil, numerous vesicle containing profiles synaptically contacted dendrites (Den) and/or spines (Sp) (Figure 2, arrowheads). Very rarely were somata the postsynaptic target (not shown). These profiles displayed typical features of nerve terminals including clear and dense-core vesicles (Figure 2, thin arrows), mitochondria, and synaptic densities (arrowheads). Consistent with previous reports in monkey (May \& Warren, 1993), three different terminal types could be distinguished in the present CG study (Figure 2). The most common type of synaptic profile was termed axon terminal type 1 ( $\mathrm{At}_{1}$, Figure $\left.2 \mathrm{~A}\right)$. These terminals contain clear, spherical vesicles, whereas dense-core vesicles are either very rare or completely absent. The $\mathrm{At}_{1}$ terminals exhibit synaptic contacts with clear, distinctly asymmetric, synaptic densities (Figure 2A, arrowheads). Type 2 axon terminals ( $\left.\mathrm{At}_{2}\right)$ look quite similar to $\mathrm{At}_{1}$ terminals ( $\mathrm{At}_{2}$, Figure $2 \mathrm{~B})$, but the vesicles are somewhat more pleomorphic, and dense-core vesicles can be detected in higher numbers (Figure 2B, thin arrows). Furthermore, the synaptic densities do not appear to be quite as asymmetric as in $\mathrm{At}_{1}$ contacts. A third axon terminal, type $3\left(\mathrm{At}_{3}\right)$, was very rare (Figure $2 \mathrm{C}$ ). This terminal type clearly differs from $\mathrm{At}_{1}$ and $\mathrm{At}_{2}$ due to the abundance of dense-core vesicles, which represent the most prominent vesicle type (Figure $2 \mathrm{C}$, small arrow). Synaptic densities were not detected in the $\mathrm{At}_{3}$ samples studied.

\section{5 | GABA-positive terminals}

By using postembedding immunogold-labeling for GABA, we investigated whether GABA expression is restricted to one of the three defined terminal types in the CG. Based on the findings with the light microscope, we focused our investigation on the perisomatic neuropil. As already observed with light microscopy, most somata were contacted by either exclusively GABA-negative (Figure 3) or exclusively GABA-positive (Figures 4 and 5) contacts located on their membranes or in the perisomatic neuropil. A typical CG neuron is shown in Figure 3D. It is surrounded by exclusively GABA-negative terminals, all of them displaying features of the $\mathrm{At}_{1}$ terminal type with clear asymmetric synaptic densities (Figure $3 \mathrm{~A}-3 \mathrm{~F}$, arrowheads). Background levels of gold particles were present in this tissue, but none of the $\mathrm{At}_{1}$ terminals were overlain by sufficient numbers of gold particles to be judged GABA-positive. Figure 4D shows a low magnification photomicrograph of a CG neuron that receives input from numerous GABA-immunogold-labeled terminals. In this case, the 
number of gold particles (small arrows) that overlie each of the terminals found in its perisomatic neuropil is clearly above background staining. These terminals are all of the $\mathrm{At}_{2}$ type, characterized by their numerous dense-core vesicles (arrows), as well as synaptic densities (arrowheads), which appear less asymmetric than $\mathrm{At}_{1}$ type densities. In order to demonstrate the details of these terminals, Figure 5A provides a higher magnification view of the region found in the box shown in Figure 4D. The higher magnification views of contacts found in this regions allow closer inspection of five GABA-positive terminals indicated by gold particles (Figure 5B-5G; thin arrows). The preferential association of GABA immunogold particles to the mitochondria, as seen here, has been observed in other studies (Beaulieu \& Somogyi, 1991). Note that the immunogold-labeled terminals contain a considerable number of dense-core vesicles (thick arrows), and accordingly they were classified as $\mathrm{At}_{2}+($ Figure $4 \mathrm{~A}-4 \mathrm{C}, 4 \mathrm{E}-4 \mathrm{~F})$. In order to verify that the immunogold labeling was a consistent feature, we examined the same terminals in semiserial or adjacent ultrathin sections. Figures $5 \mathrm{C}$ and $5 \mathrm{~F}$ show high magnification $\mathrm{EM}$ images of the same terminal in semiserial sections, as can be perceived by the cut mitochondria seen on both sections. In both images, the terminal is densely labeled with gold particles (thin arrows), indicating that the GABA immunogold staining was highly reliable.

\section{4 | DISCUSSION}

By using light and electron microscopy in conjunction with immunohistochemistry, we have demonstrated for the first time that in addition to the well established cholinergic input a subgroup of postganglionic CG neurons in monkey receives a direct synaptic input from cholinergic terminals that coexpress markers for the inhibitory transmitter GABA.

Consequently, postganglionic neurons are targeted exclusively by either cholinergic or choline/GABAergic terminals. The strong ChAT-positive input to virtually all postganglionic cholinergic neurons in the monkey CG conforms to the known organization of the efferent parasympathetic motor innervation chain (McDougal \& Gamlin, 2015; Neuhuber \& Schrödl, 2011). These efferents originate from preganglionic cholinergic motoneurons of the EdingerWestphal nucleus (EWpg) in the midbrain, whose axons travel via the oculomotor nerves to the CG (Horn et al., 2008; Kozicz et al., 2011; May, Sun, \& Erichsen, 2008b). Presently, there is no evidence with respect to which muscle targets receive parasympathetic innervation from the cells with this GABAergic input. Since the CG in monkeys contains postganglionic neurons that innervate either the ciliary muscle or the sphincter pupillae muscle, it is tempting to assume that the GABA/Chat input targets only one of these sets of postganglionic neurons in order to exert a specific function. However, denervation studies in the monkey suggest that only $3 \%$ of the whole CG neuron population innervates the sphincter pupillae muscle, whereas the vast majority of postganglionic neurons seem to control the ciliary muscle, which provides lens accommodation (Warwick, 1954). Although this percentage may be an underestimation of the pupillary population size (Erichsen \& May, 2002), the $20 \%$ of cells that receive GABA/acetylcholine (ACh) terminals in the present study does not appear to correspond to the percentage of pupillary postganglionic motoneurons observed previously in macaque monkeys. Therefore it is more reasonable to assume that the ChAT/GABA-input represents an additional input to either only ciliary muscle motoneurons (a subfraction) or to both classes of postganglionic motoneurons. 


\section{1 | Ultrastructure of nerve endings in the CG}

Our findings with respect to CG ultrastructure are consistent with previous findings in monkey (Zhang, Tan, \& Wong, 1994a; May \& Warren, 1993), where axon terminals were found to mainly contact dendritic profiles in the perisomatic neuropil, rather than somata. The presence of three different axonal terminal types based on synaptic vesicle morphology was confirmed, and therefore the previously introduced nomenclature was adopted (May \& Warren, 1993). Classically, excitatory and inhibitory synapses have been distinguished by their morphological features. Excitatory synapses possess spherical vesicles and asymmetric synaptic densities, whereas inhibitory synapses possess flattened vesicles and symmetric synaptic densities (Gray, 1969). Small clear synaptic vesicles (around 40nm) are considered to accumulate fast-acting transmitters, whereas dense-core vesicles are thought to store peptide transmitters (Torrealba \& Carrasco, 2004; for review, see Harris \& Weinberg, 2012). Considering their properties—asymmetric synaptic densities, spherical vesicles, and high frequency of occurrence- it is reasonable to assume that the $\mathrm{At}_{1}$ type represents the well established excitatory ChAT-positive input from preganglionic neurons of the EWpg that transmits the signal for muscle contraction to the sphincter pupillae and ciliary muscles (for a review, see McDougal \& Gamlin, 2015).

The selective GABA-immunogold labeling of $\mathrm{At}_{2}$ terminals characterized by a greater number of dense-core vesicles and more symmetric synaptic densities than $\mathrm{At}_{1}$ indicates that this type represents a distinct class of terminals that are different from the $\mathrm{At}_{1}$ class. Since double-immunofluorescence had shown that all GAD + terminals colocalize ChAT, it is reasonable to consider these GABA + terminals as the equivalent of $\mathrm{At}_{2}$ type at $\mathrm{EM}$ level. Zhang, Tan, and Wong (1993) also observed terminals with features of inhibitory synapses in the cat CG, and these may well correspond to the $\mathrm{At}_{2}$ type of this study.

There are very few studies demonstrating colocalization of ChAT and GABA. These used adjacent sections to visualize ChAT with pre-embedding immunohistochemistry followed by GABA postembedding immunogold methods. No differences in the ultrastructure of ChAT/ GABA-positive and -negative terminals were noted in cat striate cortex (Beaulieu \& Somogyi, 1991). However, primarily symmetric synapses decorated ChAT/GABA-positive terminals found in the laterodorsal nucleus and pedunculopontine tegmental nuclei (Jia, Yamuy, Sampogna, Morales, \& Chase, 2003), making them distinctly different from conventional ChAT-positive terminals. In the rat inferior olive, both symmetric and asymmetric synaptic densities were made by individual ChAT/GABA-positive terminals, but these were found at different postsynaptic sites (Caffe, Hawkins, \& De Zeeuw, 1996). The $\mathrm{At}_{2}$ terminals of the present study revealed uniformly "intermediate" features lying between those of classic excitatory and inhibitory terminals, in that the vesicles were somewhat more pleomorphic and the synaptic densities were less asymmetric compared to cholinergic excitatory $\mathrm{At}_{1}$ type terminals, but they did not contain frankly flattened vesicles or make perfectly symmetric contacts. It should be noted that the number of dense-core vesicles in $\mathrm{At}_{2}$ terminals suggests that they also contain peptides. So the synaptic activity that is produced by the release of ACh by these terminals is not just modulated by GABA, it may also be modified by neuropeptide release and second messenger activation. 
The morphology of $\mathrm{At}_{3}$ terminals suggests that they represent a functionally different population compared to $\mathrm{At}_{1}$ and $\mathrm{At}_{2}$ type terminals. The presence of primarily dense-core vesicles may indicate that these terminals store and release neuropeptides (for review, see Erichsen et al., 1982b; Reiner, Erichsen, Cabot, Evinger, Fitzgerald, \& Karten, 1991; Torrealba \& Carrasco, 2004;). Given that several studies demonstrated a synaptic input from peptidergic afferents to the CG (Grimes et al., 1998; Kirch et al., 1995; Zhang et al., 1994a), it is very likely that the $\mathrm{At}_{3}$ terminals represent part of this input. The lack of synaptic densities for these endings was also found in a previous study (May \& Warren, 1993). This supports the view that they may represent peptidergic endings that lack synaptic contact zones because the peptides are released by volume transmission operating through a transient pore mechanism (for a review, see Torrealba \& Carrasco, 2004).

\section{2 | Source of GABAergic input}

Our results raise the question of the origin of the GABA/ACh input to the CG. Unlike in the superior cervical ganglion of the sympathetic system in rat, where GABA-immunoreactive interneurons have been demonstrated (Wolff, Joo, Kasa, Storm-Mathiesen, toldi, \& Balcar, 1986), we did not find any evidence for GABAergic intraganglionic interneurons that might act as a possible source of GABA input to CG neurons. Theoretically, the trigeminal ganglion could provide such an input to the CG, because trigeminal fibers of the nasociliary nerve are known to enter and pass through the CG to transmit sensory information from the eye ball, including the cornea (Grimes \& von Sallmann, 1960; McDougal \& Gamlin, 2015). For example, it has been suggested that substance P-positive fibers running through the monkey CG may synapse on postganglionic neurons (Grimes et al., 1998; Zhang et al., 1994b). Although a subpopulation of GABAergic neurons has been described in the trigeminal ganglion in different species (cat: 20.0\%, Stoyanova, Dandov, Lazarov, \& Chouchkov, 1998; rat: Hayasaki, Sohma, Kanbara, Maemura, Kubota, \& Watanabe, 2006; Hayasaki, Sohma, Kanbara, \& Otsuki, 2012), nothing is known about the course of their fibers in primates, including their specific targets and whether they coexpress cholinergic markers. The significant reduction of GABA responses in the $\mathrm{CG}$ of chicken following preganglionic denervation (McEachern, Jacob, \& Berg, 1989), as well as the lack of GABAimmunoreactive terminals in dissociated embryonal chicken CG neurons after in ovo denervation (Liu et al., 2006), point instead to the preganglionic neurons in the EW as a putative source of the GABAergic input in birds (McEachern et al., 1989). To date, no GABA/ACh neurons have been described in the EWpg, so the origin of this input to the monkey CG needs to be investigated in the future.

\subsection{Cotransmission of ACh/GABA in the CG}

With confocal fluorescence microscopy, we demonstrated that GAD expression always colocalized ChAT immunoreactivity. GAD and ChAT are the key enzymes for the biosynthesis of the respective transmitters GABA and ACh, and their expression has been widely used as indicator for cholinergic and GABAergic neuronal somata and nerve endings (Murphy, Pilowski, \& Llewellyn-Smith, 1998; Strassman, Mason, Eckenstein, Baughman, \& Maciewicz, 1987). The coexpression of both enzymes in a subset of terminals targeting postganglionic neurons in the CG suggests they release both GABA and ACh from these terminals. The original concept of "one neuron releases one transmitter"-also known as 
"Dale's principle" (Eccles, Fatt, \& Koketsu, 1954)—has been challenged by many studies. The release of a primary "fast" neurotransmitter that opens receptor-gated ion channels in the postsynaptic membrane and that is accompanied by the exocytosis of "slow" neuropeptides that work through second messenger systems to modify the activity at the synapse (Tritsch, Ding, \& Sabatini, 2012; Tritsch, Oh, Gu, \& Sabatini, 2014) has been established for several decades (Jan, Jan, \& Kufler, 1979; for a review, see Vaaga, Borisovska, \& Westbrook, 2014). More recently, there is growing evidence for dualtransmitter neurons that release multiple primary fast-acting transmitters, including monoamines, ACh, and GABA (Gundersen, 2008; Jonas, Bischofberger, \& Sandkuhler, 1998), that may have synergistic effects on each other's activity (Burnstock, 1976; Root et al., 2014; Shabel, Proulx, Piriz, \& Malinow, 2014).

One has to distinguish between a mode of co-release, where two transmitters are stored and released from a single synaptic vesicle population, and cotransmission, where the transmitters are packed in different sets of vesicles (Hnasko \& Edwards, 2012; Vaaga et al., 2014). In the latter case, differential release of any transmitter is possible by the mechanisms of differential calcium sensitivity or spatial segregation of vesicles into different boutons (Vaaga et al., 2014). There are several brain regions that contain terminals releasing ACh and GABA. These include the inferior olive (rat: Caffe et al., 1996), the cortex (cat: Beaulieu \& Somogyi, 1991; rat: Saunders, Granger, \& Sabatini, 2015), the laterodorsal nucleus and the pedunculopontine tegmental nuclei (cat: Jia et al., 2003; for a review, see Granger, Mulder, Saunders, \& Sabatini, 2016). The best characterized neuron population for cotransmission of $\mathrm{ACh}$ and GABA are the starburst amacrine cells in the retina (Lee, Kim, \& Zhou, 2010). With paired recordings in whole-mount preparations of the retina of rabbit, it was shown that ACh and GABA from starburst amacrine cells act monosynaptically at direction-selective retinal ganglion cells (Lee et al., 2010; Duarte, Santos, \& Carvalho, 1999; Zhou \& Lee, 2008). Furthermore, depending on the external $\mathrm{Ca} 2$ + concentrations, the transmitters were differentially released from spatially distinct release sites (specifically, GABA release was confined to the ganglion cell dendrites, whereas ACh release sites were not spatially restricted (Lee et al., 2010; Sethuramanujam, McLaughlin, deRosenroll, Hoggarth, Schwab, $\&$ Awatramani, 2016). Due to the limitations of the applied methods for this study, we could not determine whether GABA-positive and -negative terminals originate from different preganglionic motoneurons. We also cannot tell for certain whether ACh and GABA are stored and released from the same or separate vesicles, although we certainly did not see any evidence for separate types of clear vesicles located in pools in $\mathrm{At}_{2}$ endings.

In the chicken CG, release from separate presynaptic pools is suggested by studies applying pharmacological tools and combined immunolabelling at the light and electron microscopic level (Tsen et al., 2000). The authors demonstrated the separate localization of postsynaptic excitatory nicotinic acetylcholine receptors (AChR) and inhibitory glycine receptors (GlyR) beneath the individual large calyx endings that target avian ciliary neurons exclusively. Likewise, separate clusters of AChRs and GlyRs were found associated with the postsynaptic site of individual bouton-like choroidal terminals (Tsen et al., 2000). Since glycine and GABA both increase the $\mathrm{Cl}$ - conductance in chicken CG neurons (Sorimachi, Rhee, Shimura, \& Akaike, 1997), a mechanism for GABA/ACh receptor localization similar 
to that found for Gly/ACh may be possible (Tsen et al., 2000). GABA receptor localization has not been examined yet in primate CGs.

\subsection{Functional considerations of GABA/Ach release in CG}

The function of GABA within terminals of the monkey CG is unclear. To date, a GABAergic innervation of the CG has been demonstrated and studied only in the chicken CG. In dissociated cell cultures of CG neurons of newly hatched chicks, the expression of GABA A-receptors that activate $\mathrm{Cl}$ - channels was shown by pharmacological studies (McEachern \& Berg, 1988; McEachern et al., 1985). When GABA was applied to the isolated CG of embryonic chicken, the amplitude of postsynaptic potentials in CG neurons was reduced and transmission through the $\mathrm{CG}$ after stimulation of the preganglionic nerve stump was completely blocked (McEachern et al., 1985). In the same system, an interaction of GABA and ACh was demonstrated by showing that the activation of postsynaptic nicotinic alpha-7 AChR with ACh diminished the GABA responses mediated through the closely juxtaposed GABA A receptors at postsynaptic CG neurons (Zhang \& Berg, 2007). Examples of cotransmission by GABA and ChAT, and its possible functional consequences, have been reviewed by Granger and colleagues (Granger et al., 2016). For example, GABA may act to restrict or shunt the excitation provided by $\mathrm{ACh}$ or the release of one transmitter may be used to modulate the subsequent release to future stimulation (see Shrivastava, Triller, \& Sieghart, 2011). Without the knowledge of the source of the GABA/ACh input, as well as the physiological activity of the targeted CG population, we cannot yet speculate about a specific function for cotransmission in the CG. However this is not a unique arrangement of the efferent autonomic control; a similar GABA/ACh input to postganglionic neurons is present in the rat superior cervical ganglion. Their source of this input is a subgroup of preganglionic neurons within the intermediolateral nucleus (Ito et al., 2007).

\section{5 | CONCLUSION}

The present work demonstrates, for the first time, that a subpopulation of postganglionic neurons in the mammalian CG is targeted by afferents with specific immunohistochemical and ultrastructural features indicating that they may cotransmit ACh and GABA. Further studies are necessary to explore the origin of the input and the action and potential modulatory role of this GABAergic population, in order to elucidate the functional significance of the presumed cotransmission.

\section{Acknowledgments}

Funding information

DFG Research Training Group 1091, Klinikum Großhadern, Ludwig-Maximilians-Universität, Munich, Germany (to M.B.), Grant/Award Number: HO 1639/4-4; National Institute of Health (to P.J.M. And A.K.E.H.), Grant/Award Number: EY014263.

The authors thank Ahmed Messoudi for excellent technical assistance in the Horn laboratory. We would also like to acknowledge the histological assistance of Jinrong Wei in the May laboratory, and for the careful work of Glen Hoskins in the electron microscopy suite. 


\section{References}

Barnerssoi, M., May, PJ. Postembedding immunohistochemistry for inhibitory neurotransmitters in conjunction with neuroanatomical tracers. In: Van Bockstaele, EJ., editor. Transmission electron microscopy methods for understanding the brain1. New York, NY: Springer; 2015. p. 181-203.

Beaulieu C, Somogyi P. Enrichment of cholinergic synaptic terminals on GABAergic neurons and coexistence of immunoreactive GABA and choline acetyltransferase in the same synaptic terminals in the striate cortex of the cat. Journal of Comparative Neurology. 1991; 304:666-680. [PubMed: 2013651]

Bickford ME, Wei H, Eisenback MA, Chomsung RD, Slusarczyk AS, Dankowsi AB. Synaptic organization of thalamocortical axon collaterals in the perigeniculate nucleus and dorsal lateral geniculate nucleus. Journal of Comparative Neurology. 2008; 508:264-285. [PubMed: 18314907]

Bruce G, Wainer BH, Hersh LB. Immunoaffinity purification of human choline acetyltransferase: Comparison of the brain and placental enzymes. Journal of Neurochemistry. 1985; 45:611-620. [PubMed: 4009177]

Büttner-Ennever JA, Horn AKE, Scherberger H, D'Ascanio P. Motoneurons of twitch and nontwitch extraocular muscle fibers in the abducens, trochlear, and oculomotor nuclei of monkeys. Journal of Comparative Neurology. 2001; 438:318-335. [PubMed: 11550175]

Burde RM. The pupil. International Ophthalmology Clinics. 1967; 7:839-855. [PubMed: 5607338]

Burnstock G. Purinergic receptors. Journal of Theoretical Biology. 1976; 62:491-503. [PubMed: 994531]

Caffe AR, Hawkins RK, De Zeeuw CI. Coexistence of choline acetyltransferase and GABA in axon terminals in the dorsal cap of the rat inferior olive. Brain Research. 1996; 724:136-140. [PubMed: 8816268]

Dawson TM, Dawson VL, Synder SH. A novel neuronal messenger molecule in the brain: The free radical nitric oxide. Annals of Neurology. 1992; 32:297-311. [PubMed: 1384420]

Duarte CB, Santos PF, Carvalho AP. Corelease of two functionally opposite neurotransmitters by retinal amacrine cells: Experimental evidence and functional significance. Journal of Neuroscience Research. 1999; 58:475-479. [PubMed: 10533040]

Eccles JC, Fatt P, Koketsu K. Cholinergic and inhibitory synapses in a pathway from motor-axon collaterals to motoneurones. Journal of Physiology. 1954; 126:524-562. [PubMed: 13222354]

Erichsen JT, Karten HJ, Eldred WD, Brecha NC. Localization of substance P-like and enkephalin-like immunoreactivity within preganglionic terminals of the avian ciliary ganglion: Light and electron microscopy. Journal of Neuroscience. 1982a; 2:994-1003. [PubMed: 6178809]

Erichsen JT, May PJ. The pupillary and ciliary components of the cat Edinger-Westphal nucleus: A transsynaptic transport investigation. Visual Neuroscience. 2002; 19:15-29. [PubMed: 12180856]

Erichsen JT, Reiner A, Karten HJ. Co-occurence of substance P-like and Leu-enkephalin-like immunoreactivities in neurones and fibres of avian nervous system. Nature. 1982b; 295:407-410. [PubMed: 6173764]

Erlander MG, Tillakaratne NJK, Feldblum S, Patel N, Tobin AJ. Two genes encode distinct glutamate decarboxylases. Neuron. 1991; 7:91-100. [PubMed: 2069816]

Gamlin PD, Reiner A. The Edinger-Westphal nucleus: Sources of input influencing accommodation, pupilloconstriction, and choroidal blood flow. Journal of Comparative Neurology. 1991; 306:425438. [PubMed: 1713924]

Gamlin PD, Reiner A, Erichsen JT, Karten HJ, Cohen DH. The neural substrate for the pupillary light reflex in the pigeon (Columba livia). Journal of Comparative Neurology. 1984; 226:523-543. [PubMed: 6747033]

Gamlin PDR, Zhang YH, Clendaniel RA, Mays LE. Behavior of identified Edinger-Westphal neurons during ocular accommodation. Journal of Neurophysiology. 1994; 72:2368-2382. [PubMed: 7884465]

Granger AJ, Mulder N, Saunders A, Sabatini BL. Cotransmission of acetylcholine and GABA. Neuropharmacology. 2016; 100:40-46. [PubMed: 26220313]

Gray EG. Electron microscopy of excitatory and inhibitory synapses: A brief review. Progress in Brain Research. 1969; 31:141-155. [PubMed: 4899407] 
Grimes P, von Sallmann L. Comparative anatomy of the ciliary nerves. Archives of Ophthalmology. 1960; 64:81-91. [PubMed: 13829374]

Grimes PA, Koeberlein B, Tigges M, Stone RA. Neuropeptide Y-like immunoreactivity localizes to preganglionic axon terminals in the rhesus monkey ciliary ganglion. Investigative Ophthalmology and Visual Science. 1998; 39:227-232. [PubMed: 9477979]

Gundersen V. Co-localization of excitatory and inhibitory transmitters in the brain. Acta Neurologica Scandinavica. 2008; 188(Suppl):29-33. [PubMed: 18439218]

Harris KM, Weinberg RJ. Ultrastructure of synapses in the mammalian brain. Cold Spring Harbor Perspectives in Biology. 2012; 4:a005587. [PubMed: 22357909]

Hayasaki H, Sohma Y, Kanbara K, Maemura K, Kubota T, Watanabe M. A local GABAergic system within rat trigeminal ganglion cells. European Journal of Neuroscience. 2006; 23:745-757. [PubMed: 16487155]

Hayasaki H, Sohma Y, Kanbara K, Otsuki Y. Heterogenous GABA(B) receptor-mediated pathways are involved in the local GABAergic system of the rat trigeminal ganglion: Possible involvement of KCTD proteins. Neuroscience. 2012; 218:344-358. [PubMed: 22626642]

Hnasko TS, Edwards RH. Neurotransmitter co-release: Mechanism and physiological role. Annual Review of Physiology. 2012; 74:225-243.

Horn AK, Eberhorn A, Härtig W, Ardeleanu P, Messoudi A, Büttner-Ennever JA. Perioculomotor cell groups in monkey and man defined by their histochemical and functional properties: Reappraisal of the Edinger-Westphal nucleus. Journal of Comparative Neurology. 2008; 507:1317-1335. [PubMed: 18186030]

Hultborn H, Mori K, Tsukahara N. The neuronal pathway subserving the pupillary light reflex. Brain Research. 1978; 159:255-267. [PubMed: 215267]

Ito T, Hioki H, Nakamura K, Tanaka Y, Nakade H, Kaneko T, Iino S, Nojyo Y. Gamma-aminobutyric acid-containing sympathetic preganglionic neurons in rat thoracic spinal cord send their axons to the superior cervical ganglion. Journal of Comparative Neurology. 2007; 502:113-125. [PubMed: 17335042]

Jan YN, Jan LY, Kuffler SW. A peptide as a possible transmitter in sympathetic ganglia of the frog. Proceedings of the National Academy of Sciences of the United States of America. 1979; 76:1501-1505. [PubMed: 35789]

Jia HG, Yamuy J, Sampogna S, Morales FR, Chase MH. Colocalization of $\boldsymbol{\gamma}$-aminobutyric acid and acetylcholine in neurons in the laterodorsal and pedunculopontine tegmental nuclei in the cat: A light and electron microscopic study. Brain Research. 2003; 992:205-219. [PubMed: 14625059]

Jonas P, Bischofberger J, Sandkuhler J. Corelease of two fast neurotransmitters at a central synapse. Science. 1998; 281:419-424. [PubMed: 9665886]

Kirch W, Neuhuber W, Tamm E. Immunohistochemical localization of neuropeptides in the human ciliary ganglion. Brain Research. 1995; 681:229-234. [PubMed: 7552287]

Kozicz T, Bittencourt JC, May PJ, Reiner A, Gamlin PDR, Palkovits M, Horn AKE, Toledo CAB, Ryabinin AE. The Edinger-Westphal nucleus: A historical, structural, and functional perspective on a dichotomous terminology. Journal of Comparative Neurology. 2011; 519:1413-1434. [PubMed: 21452224]

Landmesser L, Pilar G. The onset and development of transmission in the chick ciliary ganglion. Journal of Physiology. 1972; 222:691-713. [PubMed: 4338175]

Lee S, Kim K, Zhou ZJ. Role of ACh-GABA cotransmission in detecting image motion and motion direction. Neuron. 2010; 68:1159-1172. [PubMed: 21172616]

Liu Z, Neff RA, Berg DK. Sequential interplay of nicotinic and GABAergic signaling guides neuronal development. Science. 2006; 314:1610-1613. [PubMed: 17158331]

Martin AR, Pilar G. Dual mode of synaptic transmission in the avian ciliary ganglion. Journal of Physiology. 1963a; 168:443-463. [PubMed: 14062687]

Martin AR, Pilar G. Transmission through the ciliary ganglion of the chick. Journal of Physiology. 1963b; 168:464-475. [PubMed: 14062688]

Marwitt R, Pilar G, Weakly JN. Characterization of two ganglion cell populations in avian ciliary ganglion. Brain Research. 1971; 25:317-334. [PubMed: 4322855] 
May PJ, Reiner AJ, Ryabinin AE. Comparison of the distributions of urocortin-containing and cholinergic neurons in the perioculomotor midbrain of the cat and macaque. Journal of Comparative Neurology. 2008a; 507:1300-1316. [PubMed: 18186029]

May, PJ., Sun, W., Erichsen, JT. Defining the pupillary component of the perioculomotor preganglionic population within a unitary primate Edinger-Westphal nucleus. In: Kennard, C., Leigh, JR., editors. Using eye movements as an experimental probe of brain function. Amsterdam, The Netherlands: Elsevier; 2008b. p. 97-106.

May PJ, Warren S. Ultrastructure of the macaque ciliary ganglion. Journal of Neurocytology. 1993; 22:1073-1095. [PubMed: 8106881]

McDougal D, Gamlin PD. Autonomic control of the eye. Comprehensive Physiology. 2015; 5:439473. [PubMed: 25589275]

McEachern AE, Berg DK. Benzodiazepine interactions with GABAA receptors on chick ciliary ganglion neurons. Molecular Pharmacology. 1988; 34:129-135. [PubMed: 2842652]

McEachern AE, Jacob MH, Berg DK. Differential effects of nerve transection on the ACh and GABA receptors of chick ciliary ganglion neurons. Journal of Neuroscience. 1989; 9:3899-3907. [PubMed: 2555459]

McEachern AE, Margiotta JF, Berg DK. Gamma-amino-butyric acid receptors on chick ciliary ganglion neurons in vivo and in cell culture. Journal of Neuroscience. 1985; 5:2690-2695. [PubMed: 2995607]

Murphy SM, Pilowsky PM, Llewellyn-Smith IJ. Pre-embedding staining for GAD67 versus postembedding staining for GABA as markers for central GABAergic terminals. Journal of Histochemistry and Cytochemistry. 1998; 46:1261-1268. [PubMed: 9774625]

Narayanan $\mathrm{CH}$, Narayanan Y. An experimental inquiry into the central source of preganglionic fibers to the chick ciliary ganglion. Journal of Comparative Neurology. 1976; 166:101-109. [PubMed: 1262544]

Neuhuber W, Schrödl F. Autonomic control of the eye and the iris. Autonomic Neuroscience. 2011; 165:67-79. [PubMed: 21071284]

Rehm H, Wiedenmann B, Betz H. Molecular characterization of synaptophysin, a major calciumbinding protein of the synaptic vesicle membrane. EMBO Journal. 1986; 5:535-541. [PubMed: 3086086]

Reiner A, Erichsen JT, Cabot JB, Evinger C, Fitzgerald ME, Karten HJ. Neurotransmitter organization of the nucleus of Edinger-Westphal and its projection to the avian ciliary ganglion. Visual Neuroscience. 1991; 6:451-472. [PubMed: 1712628]

Reiner A, Karten HJ, Gamlin PDR, Erichsen JT. Parasympathetic ocular control. Trends in Neurosciences. 1983; 6:140-145.

Root DH, Mejias-Aponte CA, Zhang S, Wang HL, Hoffman AF, Lupica CR, Morales M. Single rodent mesohabenular axons release glutamate and GABA. Nature Neuroscience. 2014; 17:1543-1551. [PubMed: 25242304]

Saunders A, Granger AJ, Sabatini BL. Corelease of acetylcholine and GABA from cholinergic forebrain neurons. Elife. 2015; 4:e06412.

Schneider CA, Rasband WS, Eliceiri KW. NIH Image to ImageJ: 25 years of image analysis. Nature Methods. 2012; 9:671-675. [PubMed: 22930834]

Sethuramanujam S, McLaughlin AJ, deRosenroll G, Hoggarth A, Schwab DJ, Awatramani GB. A central role for mixed acetylcholine/GABA transmission in direction coding in the retina. Neuron. 2016; 90:1243-1256. [PubMed: 27238865]

Shabel SJ, Proulx CD, Piriz J, Malinow R. Mood regulation: GABA/glutamate co-release controls habenula output and is modified by antidepressant treatment. Science. 2014; 345:1494-1498. [PubMed: 25237099]

Shrivastava AN, Triller A, Sieghart W. GABA(A) receptors: Post-synaptic co-localization and crosstalk with other receptors. Frontiers in Cellular Neuroscience. 2011; 5:7. [PubMed: 21734865]

Sorimachi M, Rhee JS, Shimura M, Akaike N. Mechanisms of GABA- and glycine-induced increases of cytosolic $\mathrm{Ca} 2+$ concentrations in chick embryo ciliary ganglion cells. Journal of Neurochemistry. 1997; 69:797-805. [PubMed: 9231741] 
Stoyanova I, Dandov A, Lazarov N, Chouchkov C. GABA-and glutamate-immunoreactivity in sensory ganglia of cat: A quantitative analysis. Archives of Physiology and Biochemistry. 1998; 106:362369. [PubMed: 10441058]

Strassman A, Mason P, Eckenstein F, Baughman RW, Maciewicz R. Choline acetyltransferase immunocytochemistry of Edinger-Westphal and ciliary ganglion afferent neurons in the cat. Brain Research. 1987; 423:293-304. [PubMed: 2445447]

Torrealba F, Carrasco MA. A review on electron microscopy and neurotransmitter systems. Brain Research Reviews. 2004; 47:5-17. [PubMed: 15572159]

Tritsch NX, Ding JB, Sabatini BL. Dopaminergic neurons inhibit striatal output through non-canonical release of GABA. Nature. 2012; 490:262-266. [PubMed: 23034651]

Tritsch NX, Oh WJ, Gu C, Sabatini BL. Midbrain dopamine neurons sustain inhibitory transmission using plasma membrane uptake of GABA, not synthesis. Elife. 2014; 3:e01936. [PubMed: 24843012]

Tsen G, Williams B, Allaire P, Zhou YD, Ikonomov O, Kondova I, Jacob MH. Receptors with opposing functions are in postsynaptic microdomains under one presynaptic terminal. Nature Neuroscience. 2000; 3:126-132. [PubMed: 10649567]

Tuttle JB, Vaca K, Pilar G. Target influences on [3H]ACh synthesis and release by ciliary ganglion neurons in vitro. Developmental Biology. 1983; 97:255-263. [PubMed: 6852365]

Ugolini G, Klam F, Doldan Dans M, Dubayle D, Brandi AM, Büttner-Ennever JA, Graf W. Horizontal eye movement networks in primates as revealed by retrograde transneuronal transfer of rabies virus: Differences in monosynaptic input to "slow" and "fast" abducens motoneurons. Journal of Comparative Neurology. 2006; 498:762-785. [PubMed: 16927266]

Vaaga CE, Borisovska M, Westbrook GL. Dual-transmitter neurons: Functional implications of corelease and co-transmission. Current Opinion in Neurobiology. 2014; 29:25-32. [PubMed: 24816154]

Vasconcelos LA, Donaldson C, Sita LV, Casatti CA, Lotfi CF, Wang L, Frigo C, Lovejoy E, Bittencourt JC. Urocortin in the central nervous system of a primate (Cebus apella): Sequencing, immunohistochemical, and hybridization histochemical characterization. Journal of Comparative Neurology. 2003; 463:157-175. [PubMed: 12815753]

Wang N, Perkins E, Zhou L, Warren S, May PJ. Anatomical evidence that the superior colliculus controls saccades through central mesencephalic reticular formation gating of omnipause neuron activity. Journal of Comparative Neurology. 2013; 33:16285-16296.

Warwick B. The ocular parasympathetic nerve supply and its mesencephalic sources. Journal of Anatomy. 1954; 88:71-93. [PubMed: 13129172]

Wiedenmann B, Franke WW. Identification and localization of synaptophysin, an integral membrane glycoprotein of $\mathrm{M}_{\mathrm{r} 38,000}$ characteristic of presynaptic vesicles. Cell. 1985; 41:1017-1028. [PubMed: 3924408]

Wolff JR, Joo F, Kasa P, Storm-Mathiesen J, Toldi J, Balcar VJ. Presence of neurons with GABA-like immunoreactivity in the superior cervical ganglion of the rat. Neuroscience Letters. 1986; 71:157162. [PubMed: 3024073]

Zeeh C, Hess BJ, Horn AKE. Calretinin inputs are confined to motoneurons for upward eye movements in monkey. Journal of Comparative Neurology. 2013; 521:3154-3166. [PubMed: 23696443]

Zhang J, Berg DK. Reversible inhibition of GABAA receptors by alpha7-containing nicotinic receptors on the vertebrate postsynaptic neurons. Journal of Physiology. 2007; 579:753-763. [PubMed: 17204496]

Zhang YL, Tan CK, Wong WC. The ciliary ganglion of the cat: A light and electron microscopy study. Anatomy and Embryology. 1993; 187:591-599. [PubMed: 8214616]

Zhang YL, Tan CK, Wong WC. The ciliary ganglion of the monkey: A light and electron microscope study. Journal of Anatomy. 1994a; 184:251-260. [PubMed: 8014118]

Zhang YL, Tan CK, Wong WC. Localisation of substance P-like immunoreactivity in the ciliary ganglia of monkey (Macaca fascicularis) and cat: A light- and electron-microscopic study. Cell and Tissue Research. 1994b; 276:163-171. [PubMed: 7514500] 
Zhou ZJ, Lee S. Synaptic physiology of direction selectivity in the retina. Journal of Physiology. 2008; 586:4371-4376. [PubMed: 18617561] 

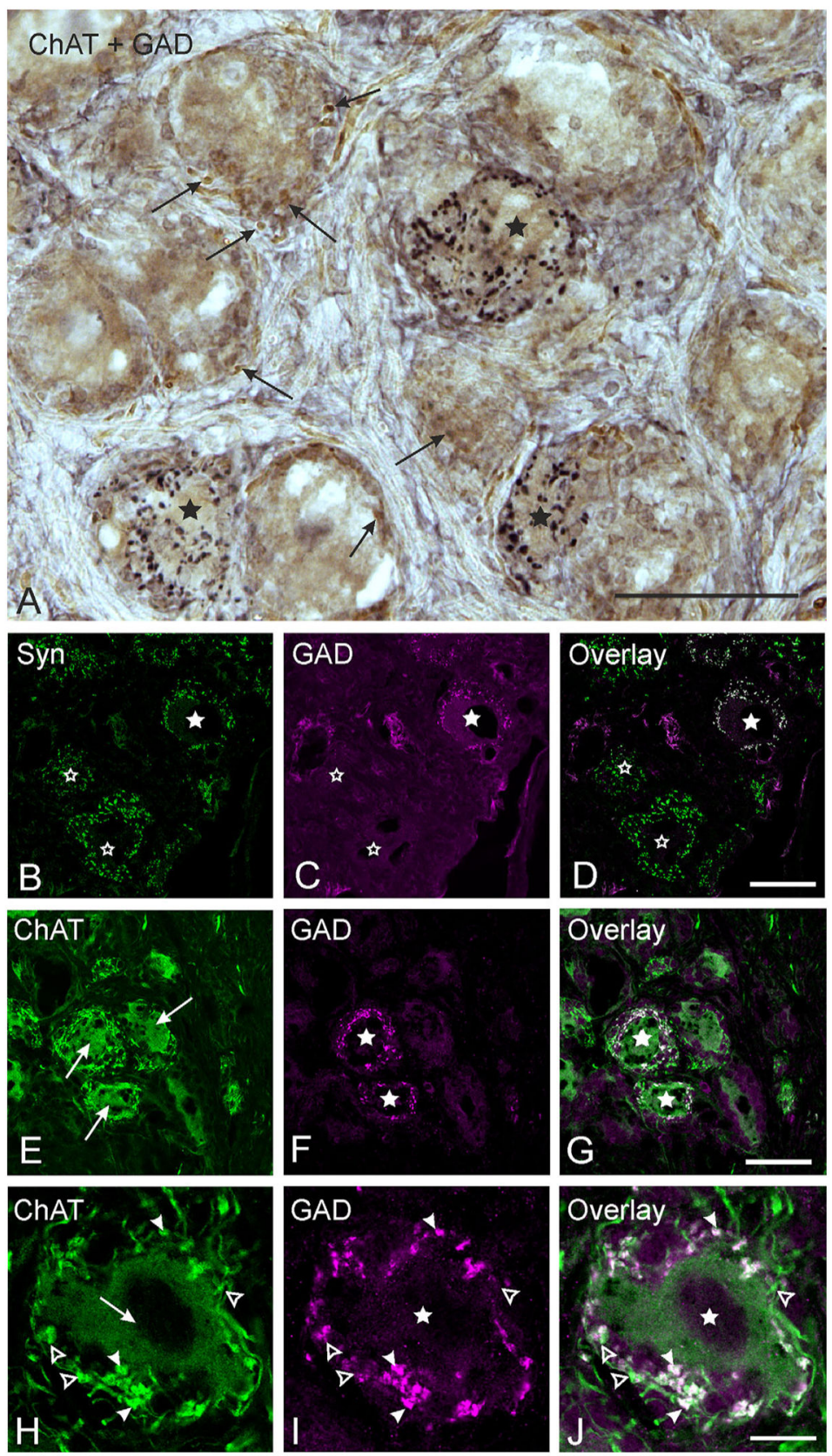

FIGURE 1.

Immunostained cryosections demonstrating gamma-aminobutyric acid (GABA)-positive terminals. Stars mark a subpopulation of choline acetyltransferase (ChAT)-positive, postganglionic ciliary ganglion (CG) neurons that receive a dense supply of glutamic acid decarboxylase (GAD)-positive boutons. A. Combined immunoperoxidase staining of a monkey CG section showing ChAT-positive neurons (brown) surrounded by ChAT-positive profiles (arrows) and/or GAD-positive bouton-like structures (black). Autofluorescent lipofuscin granules could be distinguished from immunostaining in all neurons by their color. B, C, D. Confocal images of double-immunofluorescence labeling for GAD and synaptophysin (Syn). B. Numerous green-fluorescing Syn-positive terminals supply every 
CG neuron. C. A subpopulation of CG neurons receives dense input from GAD-positive bouton-like structures coloured in magenta (filled star). The open star indicates CG neurons without GAD input. D. The overlay of both images shows that both Syn-expression (green) and GAD-expression (magenta) colocalize in boutons (white structures), proving that GADpositive boutons represent terminals. E-J. Confocal images of double-immunofluorescence staining of monkey CG sections for ChAT (green) and GAD (magenta). G and J show the overlay of $\mathrm{E}$ and $\mathrm{F}$ and $\mathrm{H}$ and I. All CG neuron somata show ChAT-immunoreactivity (E and $\mathrm{H}$, arrows). None of the $\mathrm{CG}$ neuron somata stain positively for GAD (F and I, arrows). A higher magnification of an example cell $(\mathrm{H}-\mathrm{J})$ shows that all GAD-positive boutonal endings (J, solid arrowheads) colocalize ChAT ( $\mathrm{G}$ and J, white, arrowheads), but few ChAT-positive endings lack GAD immunoreactivity (H-J, open arrowheads). Scale bars $=50 \mu \mathrm{m}$ in A; 40 $\mu \mathrm{m}$ in D (applies to B-D); $50 \mu \mathrm{m}$ in $\mathrm{G}$ (applies to $\mathrm{E}-\mathrm{G}$ ); $10 \mu \mathrm{m}$ in $\mathrm{J}$ (applies to $\mathrm{H}-\mathrm{J}$ ) 

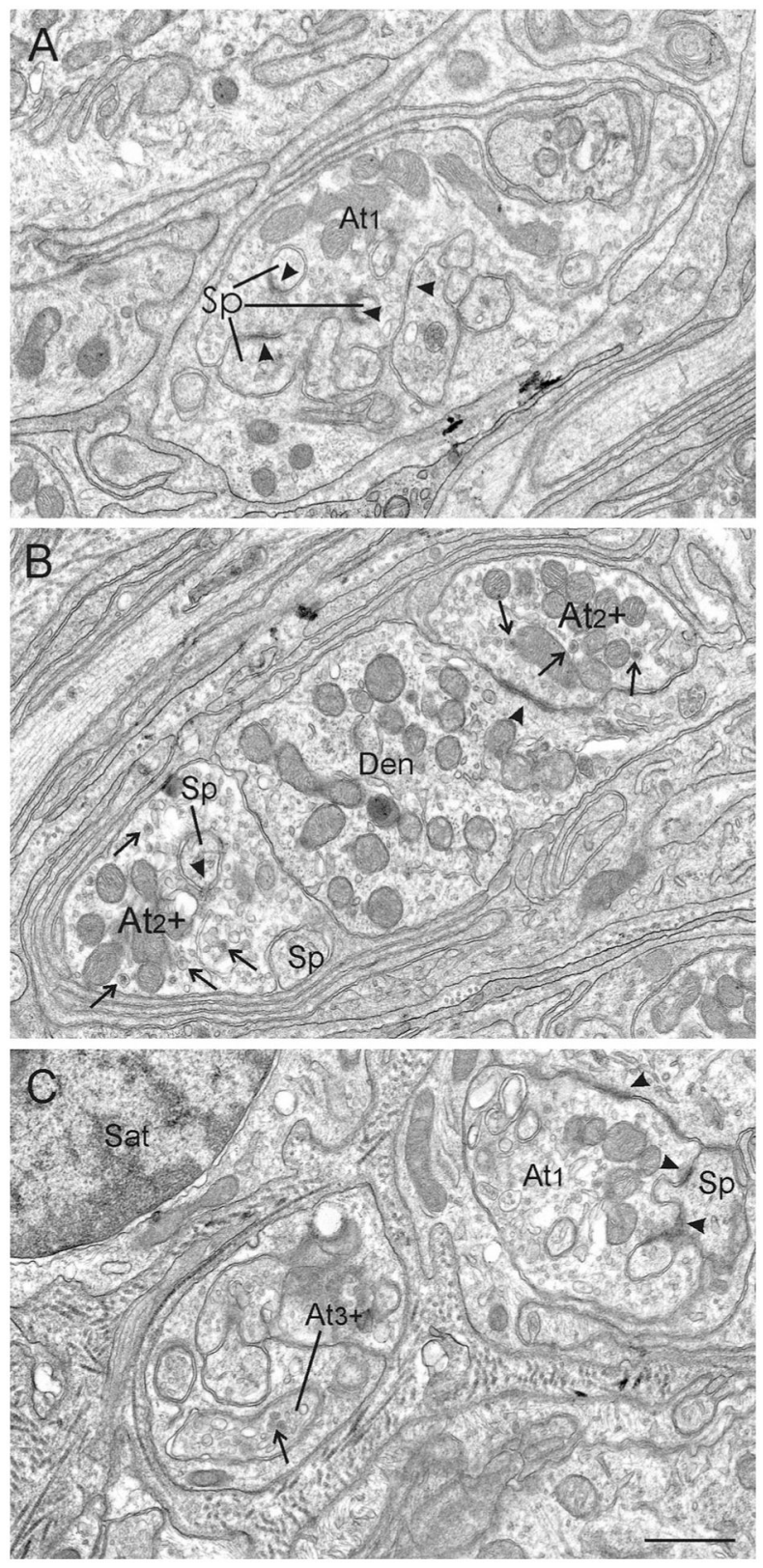

FIGURE 2.

Electron microscopic images showing three different terminal types contacting dendrites (Den) and/or spines (Sp) in the perisomatic neuropil. A. Axon terminal type $1\left(\mathrm{At}_{1}\right)$ is the most prominent terminal type in the monkey CG. It displays clear spherical vesicles, and no or very few dense-core vesicles. These terminals make distinctly asymmetric synaptic contacts (arrowheads). B. Axon terminal type $2\left(\mathrm{At}_{2}\right)$ contains somewhat more clear, pleomorphic vesicles, possesses a greater number of dense-core vesicles (arrows) and their synaptic contacts show less asymmetric appearance (arrowheads) than $\mathrm{At}_{1}$. C. Axon terminal type $3\left(\mathrm{At}_{3}\right)$ is very rare and stands out due to its large number of dense-core vesicles, which is the prominent vesicle type in these terminals (arrow). Synaptic contacts were not found in the studied samples. Abbreviations: $\mathrm{At}_{1}=$ axon terminal type $1, \mathrm{At}_{2}=$ 
axon terminal type $2, \mathrm{At}_{3}=$ axon terminal type 3 , Den $=$ dendrite, $\mathrm{Sp}=$ spine, Sat $=$ satellite cell. Scale bar $=0.8 \mu \mathrm{m}$ in $\mathrm{C}$ (applies to A-C) 

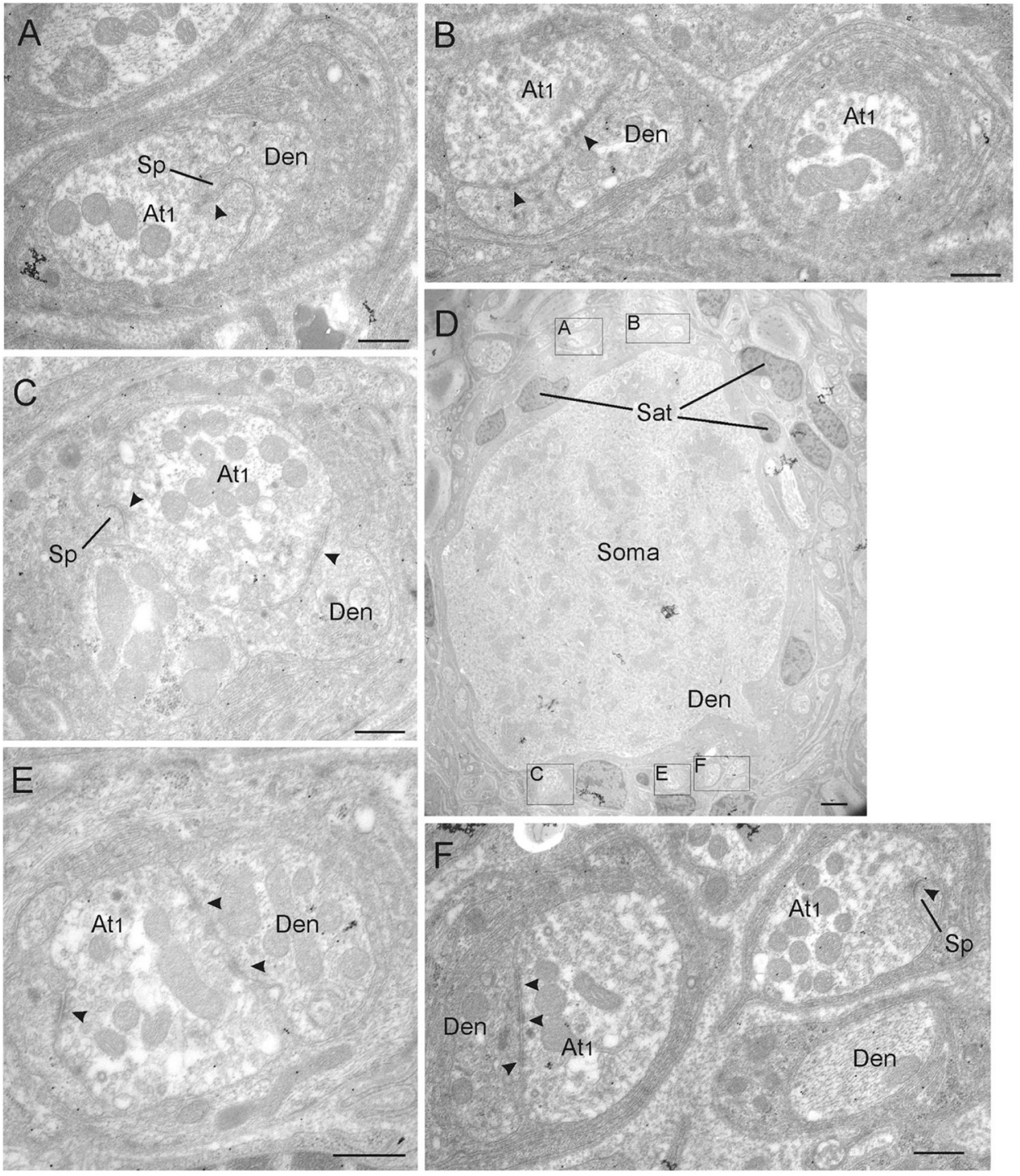

FIGURE 3.

Ultrastructure of cells receiving $\mathrm{At}_{1}$ inputs. Electron microscopic images of GABA-negative terminals from a CG section that was immunogold-labeled for GABA. The low magnification electron micrograph of a typical monkey CG neuron (D) is used to indicate the location of the higher magnification samples of $\mathrm{At}_{1}$ terminals (boxes) in the perisomatic neuropil of this neuron. Arrowheads indicate synaptic contacts. Note that all $\mathrm{At}_{1}$ terminals are GABA-negative $(\mathrm{A}-\mathrm{F})$. Abbreviations: $\mathrm{At}_{1}=$ axon terminal type 1 , Den $=$ dendrite, $\mathrm{Sat}=$ satellite cell, $\mathrm{Sp}=$ spine. Scale bar $=0.5 \mu \mathrm{m}$ in A-C, E-F; $2.0 \mu \mathrm{m}$ in D 


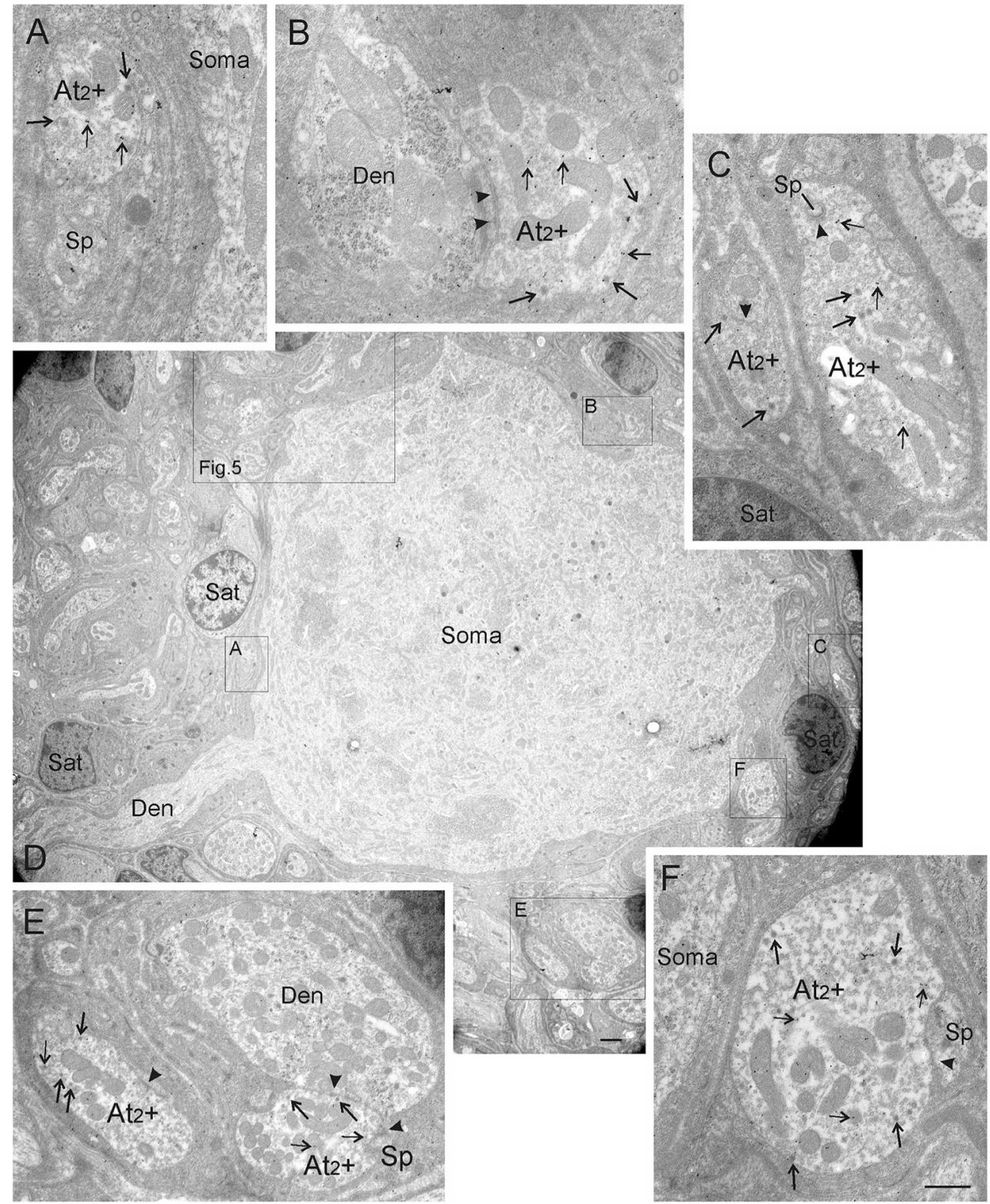

FIGURE 4.

Ultrastructure of CG cells receiving GABA-immunogold-stained $\mathrm{At}_{2}$ inputs. D shows a low magnification overview of a typical CG neuron whose perisomatic neuropil is exclusively supplied by GABA-positive terminals as indicated by the presence of immunogold particles overlaying them (thin arrows). These were classified as $\mathrm{At}_{2}$ terminals $\left(\mathrm{At}_{2}+\right.$, boxes $\left.\mathrm{A}-\mathrm{F}\right)$ by using the formerly defined criteria, (e.g. the high number of dense-core vesicles [arrows, AF]) and less asymmetric synaptic densities (arrowheads). Detailed views of immunogoldlabeled $\mathrm{At}_{2}$ terminals labeled as boxes in $\mathrm{D}$ are shown in $\mathrm{A}, \mathrm{B}, \mathrm{C}, \mathrm{E}$, and $\mathrm{F}$. A higher magnification electron micrograph of the big box is shown in Figure 5A. Abbreviations: $\mathrm{At}_{2}$ $+=$ axon terminal type 2 positively immunogold-stained for GABA, Den $=$ dendrite, Sat $=$ satellite cell, $\mathrm{Sp}=$ spine. Scale bar $=0.5 \mu \mathrm{m}$ in A-C, E-F; $2.0 \mu \mathrm{m}$ in D 

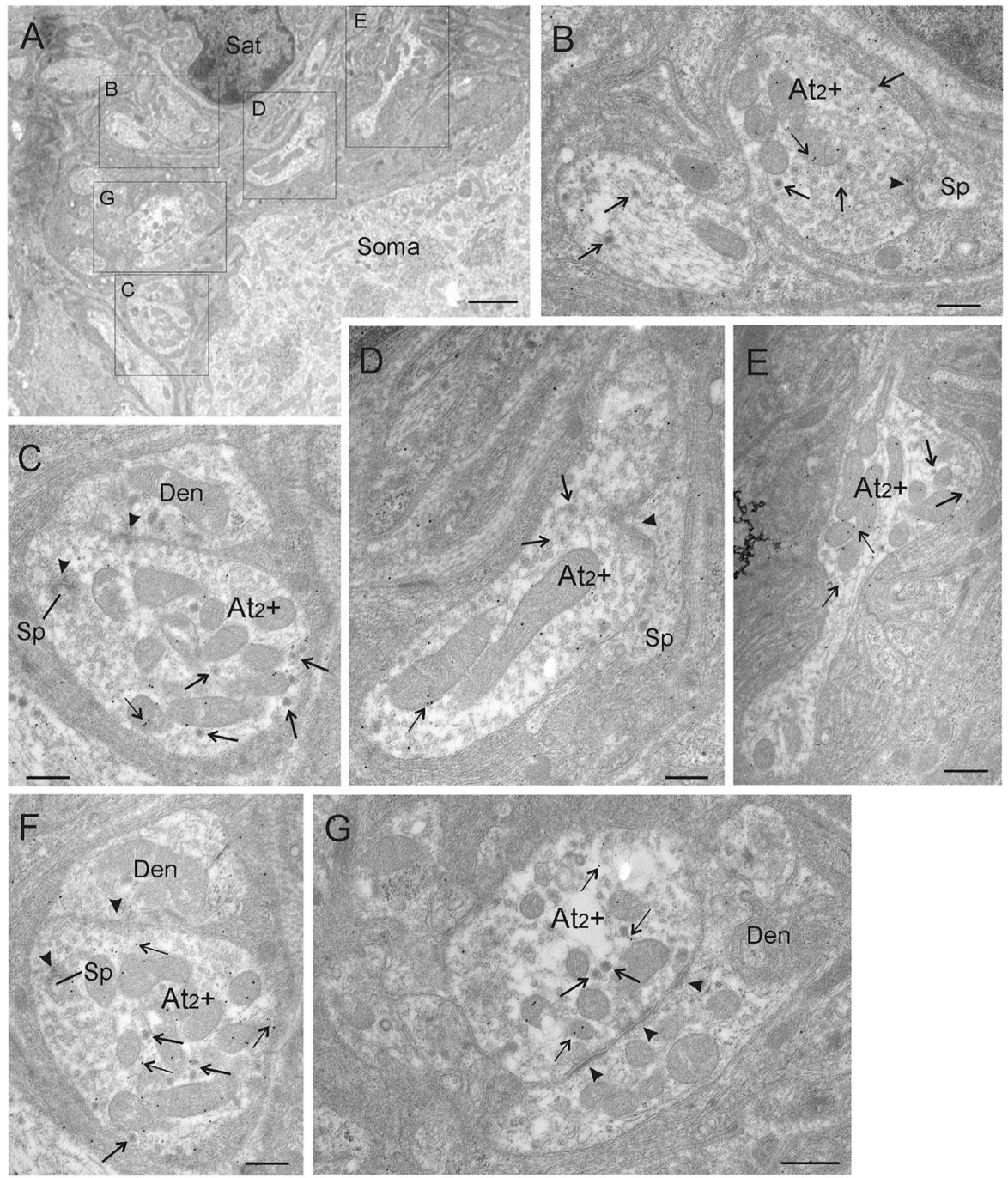

FIGURE 5.

A. Ultrastructural details of GABA-positive terminals. Higher magnification photomicrograph of the big box in Figure 4D showing another set of GABA-positive $\mathrm{At}_{2}+$ terminals supplying the same CG neuron. B-G. High magnifications are shown of the terminals indicated by labeled boxes in A. Several immunogold-particles (small arrows) overlie each $\mathrm{At}_{2}$ terminal, indicating that $\mathrm{At}_{2}$ terminals are GABA-positive (B-G). Images in $\mathrm{C}$ and $\mathrm{F}$ show the same $\mathrm{At}_{2}$ terminal in adjacent serial sections. Abbreviations: $\mathrm{At}_{2}+=$ axon terminal type 2 positively immunogold-stained for GABA, Den $=$ dendrite, Sat $=$ satellite cell, $\mathrm{Sp}=$ spine. Scale bar $=2.0 \mu \mathrm{m}$ in $\mathrm{A} ; 0.5 \mu \mathrm{m}$ in $\mathrm{B}-\mathrm{G}$ 


\section{TABLE 1}

Overview of antibody characteristics

\begin{tabular}{|c|c|c|c|}
\hline Antigen & Immunogen & Manufacturer & Concentration \\
\hline Cholinacetyltransferase (ChAT) & Human placental ChAT & $\begin{array}{l}\text { Millipore; goat polyclonal } \\
\text { antibody; AB144p; } \\
\text { RRID:AB_2079751 }\end{array}$ & $\begin{array}{l}1: 100 \text { (IP) } \\
1: 25 \text { (IF) }\end{array}$ \\
\hline Glutamic acid decarboxylase $\left(\mathrm{GAD}_{65 / 67}\right)$ & $\begin{array}{l}\text { Synthetic peptide, amino acid sequence } \\
\text { [C] DFLIEEIERLGQDL from rat } \\
\text { glutamate decarboxylase }\left(\mathrm{GAD}_{65} ; \mathrm{C}-\right. \\
\text { terminus residues [Cys] } 1572-585)\end{array}$ & $\begin{array}{l}\text { Millipore; rabbit polyclonal } \\
\text { antibody; AB1511; } \\
\text { RRID:AB_90715 }\end{array}$ & $\begin{array}{l}1: 2000(\text { IP) } \\
1: 500 \text { (IF) }\end{array}$ \\
\hline Synaptophysin (Syn) & Presynaptic vesicles from bovine brain & $\begin{array}{l}\text { Dako; M0776; clone SY38; } \\
\text { monoclonal mouse antibody; } \\
\text { RRID:AB_2199013 }\end{array}$ & $1: 20(\mathrm{IF})$ \\
\hline Gamma-aminobutyric acid (GABA) & GABA-conjugated to BSA & $\begin{array}{l}\text { Sigma-Aldrich; rabbit polyclonal; } \\
\text { A2052; RRID: AB_47765 }\end{array}$ & $1: 75(\mathrm{EM})$ \\
\hline
\end{tabular}

$\mathrm{IP}=$ immunoperoxidase method; IF = immunofluorescence method; $\mathrm{EM}=$ electron microscopy 